\title{
Enhancement of Flotation Performance of Oxidized Coal by the Mixture of Laurylamine Dipropylene Diamine and Kerosene
}

\author{
Qingshan Zhang ${ }^{1}{ }^{\oplus}$, Chenkai Niu $^{1}$, Xiangning Bu ${ }^{1, *}$,, Muhammad Bilal ${ }^{2} \oplus$, Chao $\mathrm{Ni}^{1, *}$ and Yaoli Peng ${ }^{1}$ \\ 1 Key Laboratory of Coal Processing and Efficient Utilization (Ministry of Education), School of Chemical \\ Engineeringand Technology, China University of Mining and Technology, Xuzhou 221116, China; \\ TS19040101A31@cumt.edu.cn (Q.Z.); nck@cumt.edu.cn (C.N.); peng_yaoli@163.com (Y.P.) \\ 2 Department of Mining Engineering, Balochistan University of Information Technology Engineering and \\ Management Sciences (BUITEMS), Quetta 87300, Pakistan; bilalkhan4p@gmail.com \\ * Correspondence: xiangning.bu@foxmail.com (X.B.); sunnichao@126.com (C.N.)
}

Citation: Zhang, Q.; Niu, C.; Bu, X.; Bilal, M.; Ni, C.; Peng, Y.

Enhancement of Flotation

Performance of Oxidized Coal by the Mixture of Laurylamine Dipropylene Diamine and Kerosene. Minerals 2021, 11, 1271. https://doi.org/10.3390/ $\min 11111271$

Academic Editor: Cyril O'Connor

Received: 16 October 2021

Accepted: 13 November 2021

Published: 16 November 2021

Publisher's Note: MDPI stays neutral with regard to jurisdictional claims in published maps and institutional affiliations.

Copyright: () 2021 by the authors. Licensee MDPI, Basel, Switzerland. This article is an open access article distributed under the terms and conditions of the Creative Commons Attribution (CC BY) license (https:// creativecommons.org/licenses/by/ $4.0 /)$.

\begin{abstract}
Conventional hydrocarbon oil cannot adhere effectively to oxidized coal, resulting in a low yield of clean coal. In this study, a high-speed homogenizer was used to emulsify LDD (laurylamine dipropylene diamine) and kerosene, which enhanced the flotation efficiency of oxidized coal. The flotation results showed an increase from $4.12 \%$ (only kerosene) to $23.33 \%$ (emulsified oil). An increase in contact angle indicated that the mixture reagent can increase the hydrophobicity of coal particles, which is attributed to the adsorption of LDD onto the coal particle surface and the decrease of the oil droplet A lower surface tension of LDD allows it to produce a stable layer of froth than the layer generated by kerosene alone.
\end{abstract}

Keywords: flotation of oxidized coal; laurylamine dipropylene diamine; emulsified kerosene; froth stability; coal hydrophobicity

\section{Introduction}

Coal is important non-renewable fossil energy and plays an important role in world energy. With the reduction of coal resources in the world, low-rank coal has become more and more important in social development due to its low mining cost, easy access, and high storage capacity in China, which is about 812.8 billion tons [1]. However, due to the short coal formation time of low-rank coal, the aromatic rings in its macromolecular structure are not closely arranged, and many oxygen-containing heterocyclic rings and side-chain structures can be seen. High ash content, volatile matter, moisture, and low calorific value, significantly affect the quality of clean coal [2]. Hence cleaning of low-rank coal is required [3].

Froth flotation is an effective and economical method for recovering and upgrading fine coal particles $(<0.5 \mathrm{~mm})$. One of the most important factors affecting coal flotation performance is the amount of oxygen-containing functional groups [2]. It is well known that there are a large number of oxygen-containing groups on the surface of low-rank coals, such as carboxyl, hydroxyl, carbonyl, and methoxy [3], making it difficult to float using only conventional oily collectors (kerosene and diesel) [2-7]. However, some studies have shown that when surfactants are added together with oil, the flotation performance of coal can be improved. When surfactants are added as emulsifiers, they help the oil disperse into fine droplets thus increasing the number of fine oil droplets [8]. Due to the increase in the number of oil droplets, the probability of collision between coal particles and oil droplets is increased, thus improving flotation kinetics [5]. On the other hand, surfactants also reduce the high energy input required for the diffusion of oil collectors on the coal surface through adsorption at the coal/water interface and coal/oil interface [9]. At low concentrations, such surfactants make coal hydrophobic, and at high concentrations, they make coal hydrophilic [10]. If the surfactant promotes the diffusion and adhesion 
of oil, the hydrophobicity of coal will increase, resulting in a high probability of bubbles adhering to coal particles [9]. On the other hand, if high concentrations of surfactants were used in flotation, coal surface hydrophobicity would decrease, resulting in lower concentrate recovery.

Surfactants used to improve low-rank coal/oxidized coal are divided into three categories, namely non-ionic, anionic, and cationic surfactants. For non-ionic surfactants, Furstenau et al. [11] aimed at the problem of low dispersion of kerosene in the slurry, using triethanolamine oleic acid soap as a non-ionic surfactant to disperse kerosene into small droplets in the slurry, enhance the adsorption of kerosene on the surface of coal. Zhu et al. used ethoxylated 2, 4, 7, 9-tetramethyl-5-decyne-4, 7-diol, Sulfonyl (R) 485 as raw materials, aiming at the problems of instability and easy delamination of ordinary emulsifiers, the Gemini nonionic surfactant produced by it has good stability, with a dispersion index of less than 0.06 , and a stable and effective surfactant is produced [12]. Lin Li et al. [6] prepared an emulsified collector with NP-10/n-pentanol/diesel/water, reduce the particle size of diesel, reduce the required quality of diesel by $70 \%$, reduce the amount of foaming agent, however, the emulsified collector has a slightly poorer selectivity, and the ash content of the clean coal has increased. For cationic and anionic surfactants, Liu and Liu [13] studied the effect of surfactants with different structures on the surface hydrophobicity of low-rank coals, as a result, the polar groups of the cationic surfactant are adsorbed on the surface of the low-rank coal with negative electricity through the action of strong electrostatic force. Make the hydrophobic alkyl chain facing outward, effectively improving the hydrophobicity of low-rank coal, the polar groups of anionic surfactants have an electrostatic repulsion effect on the surface of low-rank coals, making it impossible to effectively improve the hydrophobicity. Li et al. [14] adopted cetyltrimethylammonium bromide (CTAB) and sodium dodecyl sulfate (SDS) as cationic and anionic surfactants, after comparing the flotation results, it is found that the anionic surfactant SDS can slightly change the surface properties of low-rank coals and improve the selectivity and collection of kerosene. Chen et al. [15] used CTAB as a cationic surfactant to deal with the problem that the surface of low-deteriorated coal is usually negatively charged and causes electrostatic repulsion between bubbles and particles, the adsorption of CTAB changes the zeta potential of coal, enhance the adsorption of low-rank coal and kerosene collector. Vamvuka and Agridiotis [16] found that the addition of amine cationic surfactant dodecyl amine (DDA) can improve the hydrophobicity of lignite, in low-rank coal flotation, the electronegativity of the surface of low-rank coal is neutralized, the flotation performance of low-rank coal can be improved under the condition of adding a small amount of chemicals. Zhen et al. [17] showed that as the concentration of dodecyl trimethyl ammonium chloride (DTAB) increases, the surface free energy of low-rank coal is reduced, indicating that the hydrophilicity of low-rank coal is obviously suppressed, and the hydrophobicity of low-rank coal is improved.

Various surfactants have been used for improving the flotation performance of lowrank coals and oxidized coals in the literature. Flotation performance is determined by the combined action of pulp zone and froth zone [18]. The collection of hydrophobic particles occurs in the pulp zone, which is the determining step for efficient flotation separation [19]. Meanwhile, froth structure and froth stability in the froth zone are known to play a significant role in determining the recovery of valuable particles in a flotation operation [18]. Most of the related studies are on the improvement of the hydrophobicity of the coal surface for oxidized coal and low-rank coal. Ni et al. [20] applied polyoxymethylene sorbitan monostearate (Tween 80 ) to improve the flotation performance of fine lignite separation. They proposed that the enhancement of the froth properties by Tween 80 was the main reason for the increase in the combustible matter recovery of lignite in flotation. In addition to the emulsification of surfactants to an oily collector, Niu et al. [21] also found that lower surface tension resulting from the presence of sodium cocoyl glycinate offset the negative impact of oily collector, providing a more stable froth layer. LDD is used as a disinfectant for instruments in medicine and dentistry and for germ reduction on solid 
surfaces in the food industry. Meanwhile, LDD is also used in closed water cycles, such as in the paper industry and in cooling towers, and for the preservation of cooling lubricants, such as drilling and cutting oils, where its dispersant, lubricant and corrosion protection properties are also useful.

On this basis, this study explored the potential of LDD as a promoter for the flotation of oxidized coal using kerosene. To the best of our knowledge, the use of LLD as an emulsifier for the flotation of oxidized coal has not been reported. The improvement of flotation yield of oxidized coal by LDD was investigated from the perspectives of the improvements of the coal surface hydrophobicity and froth stability. Measurement results of the X-ray photoelectron spectroscopy (XPS) test, Fourier transform infrared (FTIR) spectrum test, contact angle test, and particle size distribution of oil droplets were used to evaluate the role of the adsorption of LDD and the oil droplet size on the hydrophobicity of the coal surface. Meanwhile, measurement results of the surface tension test and froth height were employed to investigate the effect of the mixture reagent on the froth zone.

\section{Materials and Methods}

\subsection{Materials}

The clean coal sample ( $<0.5 \mathrm{~mm}$ size having $3.6 \%$ ash content) used in this study was obtained from the Taixi Anthracitex coal preparation plant. The result of the proximate analysis is listed in Table 1. Figure 1 shows the particle size distribution of the feed. To obtain the oxidized coal with different degrees of oxidation, the clean coal sample was oxidized with $3 \%$ medical hydrogen peroxide at different times at room temperature. Finally, oxidized coal samples were obtained with oxidation times of 12, 24, 36, and $48 \mathrm{~h}$. LDD (molecular formula: $\mathrm{C}_{18} \mathrm{H}_{41} \mathrm{~N}_{3}$ ) was selected as the surfactant. The FTIR spectrum and molecular structure of LDD are shown in Figures 2 and 3 respectively. The kerosene, sec-octanol, and LDD were purchased from Aladdin (AR, 98\%).

Table 1. The proximate analysis of coal sample.

\begin{tabular}{cccc}
\hline $\mathbf{M}_{\text {ad }}(\mathbf{\%})$ & $\mathbf{A}_{\text {ad }}(\%)$ & $\mathbf{V}_{\text {daf }}(\mathbf{\%})$ & FC $_{\text {daf }}(\mathbf{\%})$ \\
\hline 2.41 & 3.50 & 35.62 & 58.47 \\
\hline
\end{tabular}

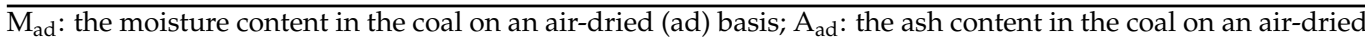
(ad) basis; $V_{\text {daf }}$ : the volatile content in the coal on dry ash-free (daf) basis; $\mathrm{FC}_{\mathrm{daf}}$ : the fixed carbon content in the coal on dry ash-free (daf) basis.

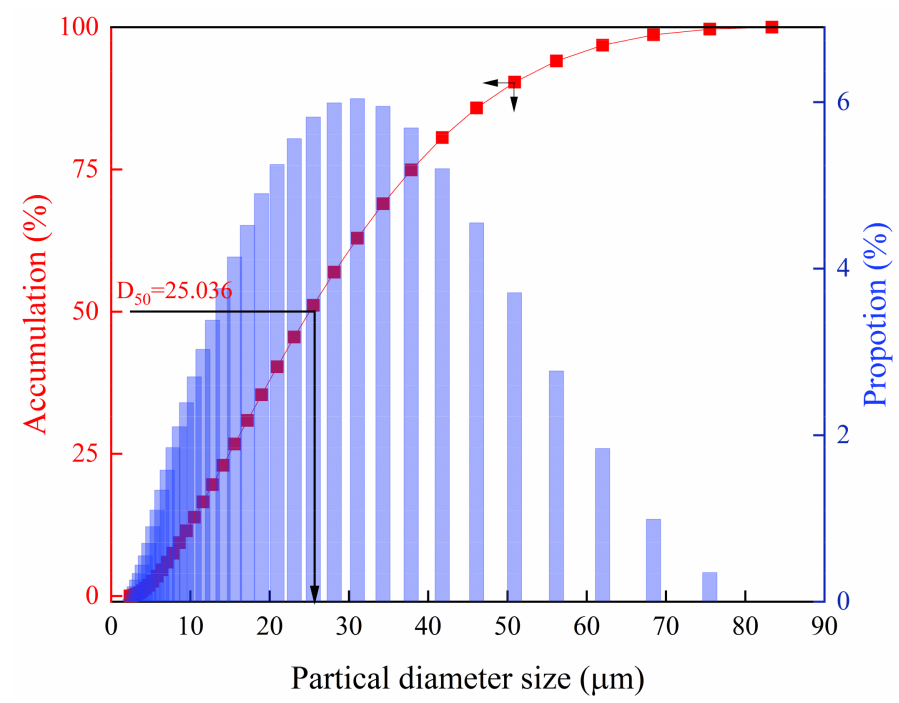

Figure 1. Size distribution and proportion of feed. 


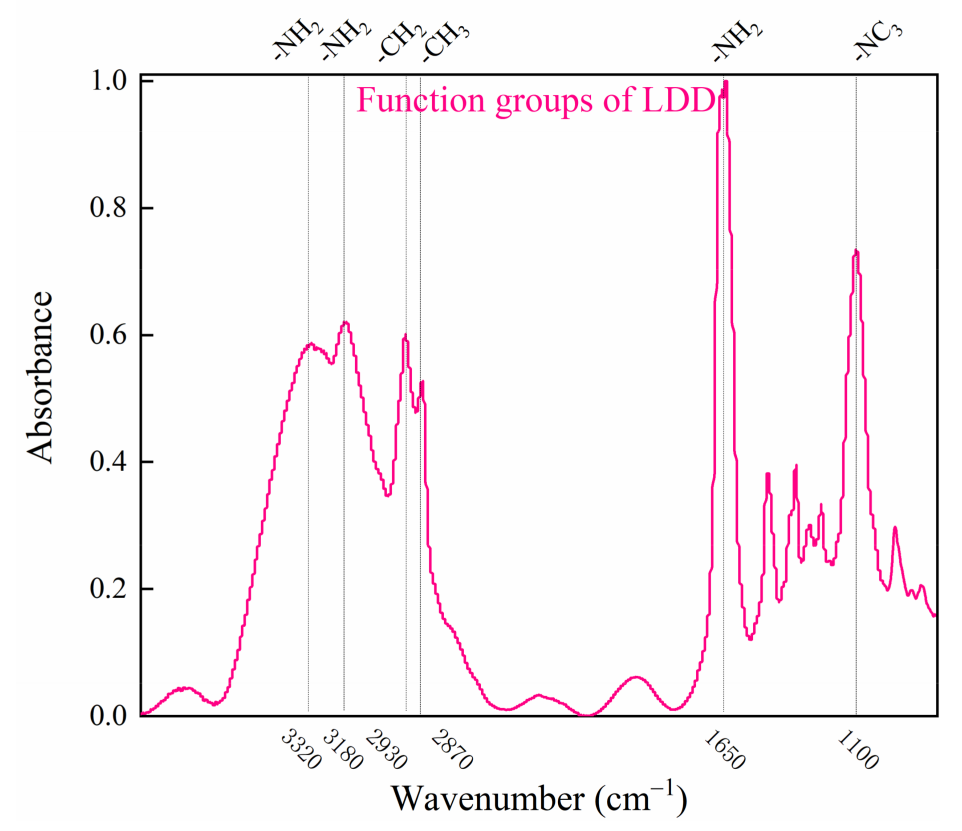

Figure 2. FTIR spectrum of LDD.

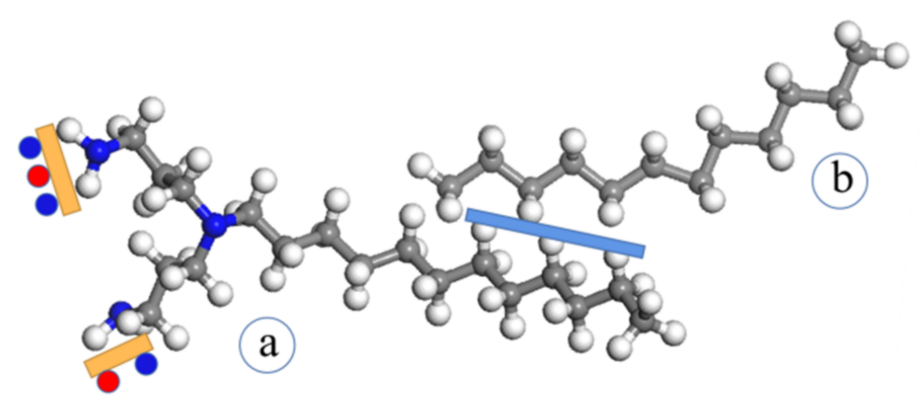

$\begin{array}{llll}\text { Carbon } & \text { Hydrogen } & \text { a-LDD } & \text { Hydrogen bond } \\ \text { Nitrogen } & \text { Oxygen } & \text { b-Kerosene } & \text { Van der waals force }\end{array}$

Figure 3. The adsorption between LDD and kerosene (a diagram of molecular structure).

The mixture reagent included $25 \mathrm{~g}$ LDD, $20 \mathrm{~g}$ kerosene and $30 \mathrm{~g}$ water. The mixture was emulsified by a high-speed homogenizer (FA25, FLUKO Shanghai Equipment Co., Ltd., Shanghai, China). The impeller speed and the treatment time for the mixture reagent were 19,000 rpm and $10 \mathrm{~min}$, respectively. In the control experiments, the collector and frother were kerosene and sec-Octyl alcohol, respectively.

\subsection{Methods}

\subsubsection{Particle Size Distribution of Oil Droplets}

The particle size distribution of oil droplets was measured by a GSL-1000 laser particle distribution meter (Liaoning Instrument Research Institute Co., Ltd, Dandong, China).

\subsubsection{Surface Tension Test}

Surface tensions of LDD solutions were measured by the JK990D automatic tension meter (Shanghai Zhongchen Digital Technology Equipment Co., Ltd., Shanghai, China). The test is carried out using a platinum ring with a diameter of $19.69 \mathrm{~mm}$. The trigger tension of this method is $0.5 \mathrm{mN} / \mathrm{m}$. The ring is inserted vertically into the solution and then raised to determine the gas-liquid interfacial tension. The platinum ring was washed 
with ethanol and deionized water and then burned to remove residual organic matter before testing. Three parallel tests were performed to ensure accuracy.

\subsubsection{Contact Angle Measurement}

The coal sample having a particle size less than $0.074 \mathrm{~mm}$ was put into the slurry (solid concentration $60 \mathrm{~g} / \mathrm{L}$ ) of emulsified oil and kerosene only in a $100 \mathrm{~mL}$ pool. After that, the sample was dried at $40{ }^{\circ} \mathrm{C}$ and was compressed with a tablet press at a pressure of $60 \mathrm{MPa}$. Contact angle measurement apparatus (JC2000D1, Shanghai Zhongchen Digital Technic Apparatus Co., Ltd., Shanghai, China) was used for measuring the contact angle. The measurement procedure has been described previously [22]. The contact angles were measured at different positions on the surface of the plate (5 times). In the case of kerosene, its amount was fixed at $500 \mathrm{~g} / \mathrm{t}$.

\subsubsection{XPS Analysis}

The XPS tests were carried out using ESCALAB 250xi (Thermo Fisher, Waltham, MA, USA). The XPS data were analyzed by XPSPEAK version 4.1 Software. XPSPEAK is a free, fully featured, software for the analysis of XPS spectra written by Raymund Kwok. The binding energy was corrected based on the $284.8 \mathrm{eV}$ carbon-carbon bond in the carbon element. The samples used for XPS tests were the same as that of contact angle measurement.

\subsubsection{FTIR Test}

Functional groups distribution of coal surface before and after treatment were determined by Spectroscopy Vertex 80v, Bruker (Billerica, MA, USA), Germany transform infrared spectrometer, using potassium bromide tablet method. The wavenumber is at the range of $3600-800 \mathrm{~cm}^{-1}$. The resolution is better than $0.06 \mathrm{~cm}^{-1}$ and the wavenumber accuracy is better than $0.01 \mathrm{~cm}^{-1}$.

\subsubsection{Flotation Test}

A standard laboratory RK/FD-II sub-aeration flotation cell with $0.5 \mathrm{~L}$ volume (Wuhan Rock Crush \& Grand Equipment Manufacture Co., Ltd, Wuhan, China) was used in the conventional flotation experiments. The impeller speed, airflow rate, and flotation time were $1900 \mathrm{r} / \mathrm{min}, 0.25 \mathrm{~m}^{3} / \mathrm{h}$, and $3 \mathrm{~min}$, respectively. A detailed description of the working process of the mechanical flotation cell is reported in the literature [23,24].

\section{Results and Discussion}

\subsection{Comparisons of Flotation Performance between Emulsified Oil and Kerosene}

Figure 4 shows the contact angles of oxidized coals under different oxidization times. The contact angle of the raw coal is $83^{\circ}$. With the increasing, degree of oxidation, the contact angle of the coal surface decreased from $83^{\circ}$ to $30^{\circ}$. The low contact angle indicates that the hydrophilic surface of coal, mainly due to the presence of a larger amount of hydrophilic functional groups, such as $\mathrm{C}=\mathrm{O}, \mathrm{C}-\mathrm{O}$, and $\mathrm{COOH}$ [25]. Figure 4 shows the flotation results of coal treated with kerosene and the mixture reagent (emulsified kerosene). The yield of clean coal decreases from $6.23 \%$ to $1.35 \%$ with the increase of oxidation degree, which is in line with the experimental results of contact angles in Figure 4. Thus, it is difficult to efficiently recover oxidized coal when a conventional flotation collector is employed. However, there are few hydrophobic functional groups, such as $\mathrm{C}-\mathrm{H}$ and $\mathrm{C}-\mathrm{C}$, which can promote the adsorption of an oily collector on coal surface due to hydrophobic bonding [26]. 


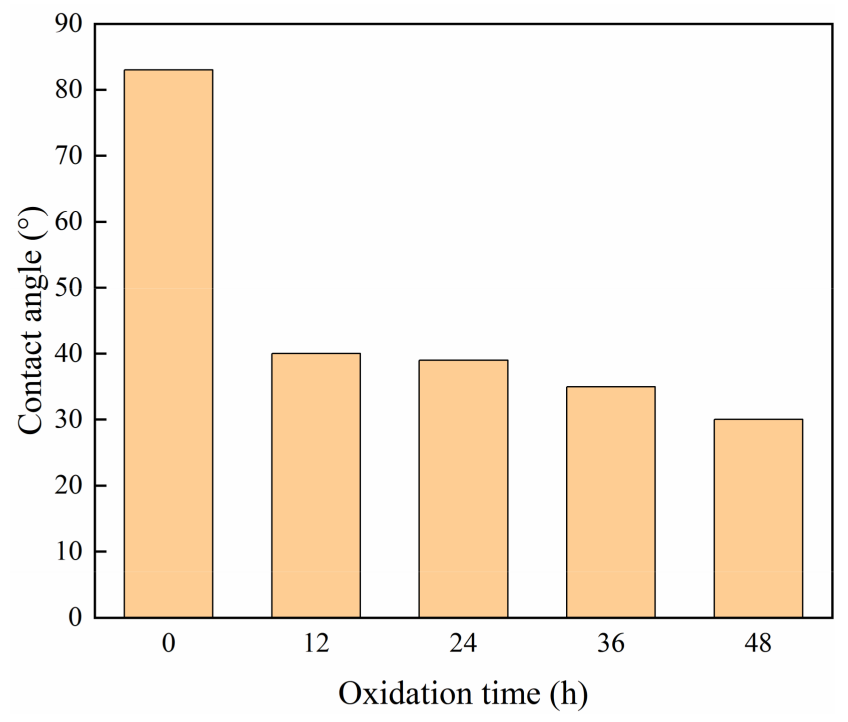

Figure 4. Contact angles of oxidized coals under different oxidization times.

It can be observed from Figure 5, in comparison with kerosene only, emulsified kerosene significantly increases the flotation yield of oxidized coal. As compared to kerosene, the application of the mixture reagent increases the flotation yield from $4.12 \%$ to $23.33 \%$ for oxidized coal with a 24 -h oxidation time. As a result, compared to conventional flotation reagents (sec-Octyl alcohol + kerosene), emulsified kerosene is superior at promoting the flotation of oxidized coal. According to Figure 6, increasing the emulsified kerosene dosage can further increase flotation yield from $26.43 \%$ to $39.65 \%$. Emulsified kerosene retains more flotation yield due to the improved hydrophobicity of the oxidized coal surface (see Section 3.2) and the generation of a stable froth (see Section 3.3).

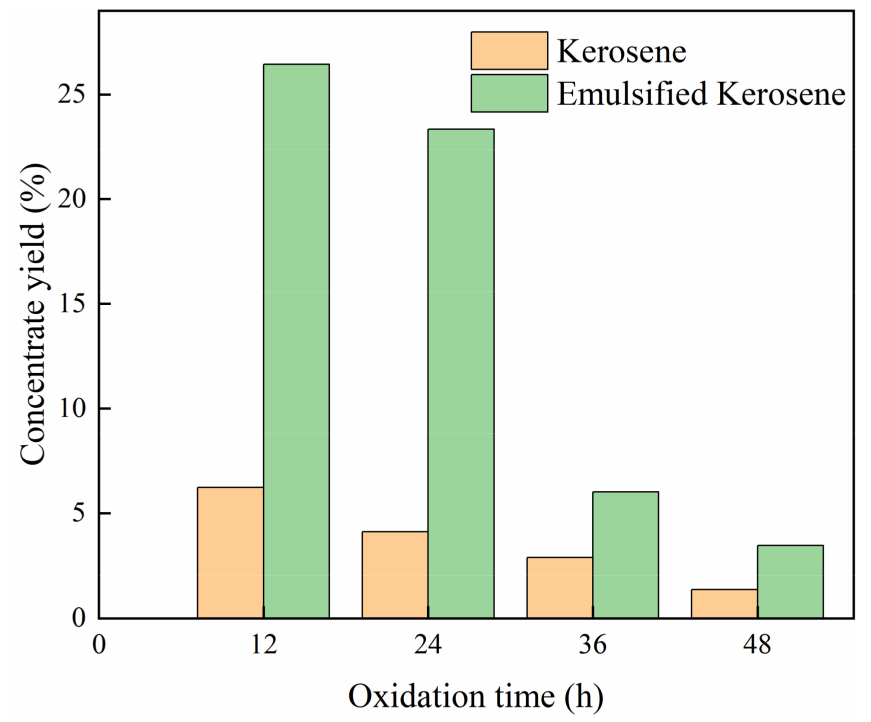

Figure 5. Comparison of flotation yields of different oxidized coals between emulsified kerosene and kerosene. For conventional flotation (kerosene+ sec-Octyl alcohol), the collector and frother dosages were $500 \mathrm{~g} / \mathrm{t}$ kerosene and $167 \mathrm{~g} / \mathrm{t}$ sec-Octyl alcohol, respectively. For the mixture reagent (emulsified kerosene), the equivalent kerosene dosage was also kept as $500 \mathrm{~g} / \mathrm{t}$ as a control test. 


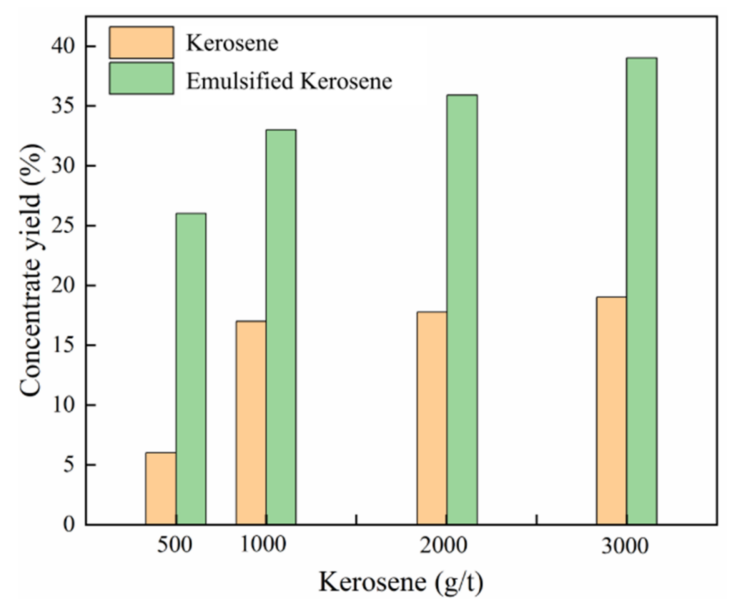

Figure 6. Comparisons of flotation yields of oxidized coal (12 h oxidation time) between kerosene and emulsified kerosene under various flotation reagent dosages. For conventional conditions, the weight ratio of kerosene and sec-Octyl alcohol was 3:1. For the mixture reagent (emulsified kerosene), the equivalent kerosene dosage was also kept as $500 \mathrm{~g} / \mathrm{t}$ as a control test.

Based on the yield of clean coal in Figure 6, when $500 \mathrm{~g} / \mathrm{t}$ of emulsified kerosene was used as the collector, the concentrate yield was $26.43 \%$. However, the concentrate yield is merely $18 \%$ when $3000 \mathrm{~g} / \mathrm{t}$ of kerosene is exclusively employed as a collector, which means $2500 \mathrm{~g} / \mathrm{t}$ of kerosene was saved when the flotation was assisted with LDD. Taking these considerations to calculate the economic benefits: The market price of kerosene and secondary octanol is 8000 and 7800 yuan per ton respectively, and the counterpart of LDD is 8000 yuan/t. After calculation, the cost is about 31 yuan per ton using kerosene exclusively and when emulsified kerosene (kerosene assisted with LDD) is used as the collector, the cost is about 9 yuan per ton. Thus, based on the above calculation, the application of LDD is feasible in an economic aspect.

Figures 7 and 8 show the particle size distribution of clean coal using emulsified kerosene and only kerosene as collectors, respectively. The particle size distribution of the clean coal in using emulsified kerosene is larger $\left(D_{50}=18.39 \mu \mathrm{m}\right)$ as compared to the size distribution of clean coal using only kerosene $\left(D_{50}=11.69 \mu \mathrm{m}\right)$. It shows that using emulsified kerosene as a collector can float large particles of coal that cannot be floated by using only kerosene as a collector. The ash test experiment revealed that with emulsified kerosene and kerosene as collectors, clean coal with a $2.5 \%$ ash content was obtained, which indicates that the distribution of ash material in this coal sample is homogeneous. Thus, emulsified kerosene can be used as a collector to increase the yield of clean coal without increasing ash content.

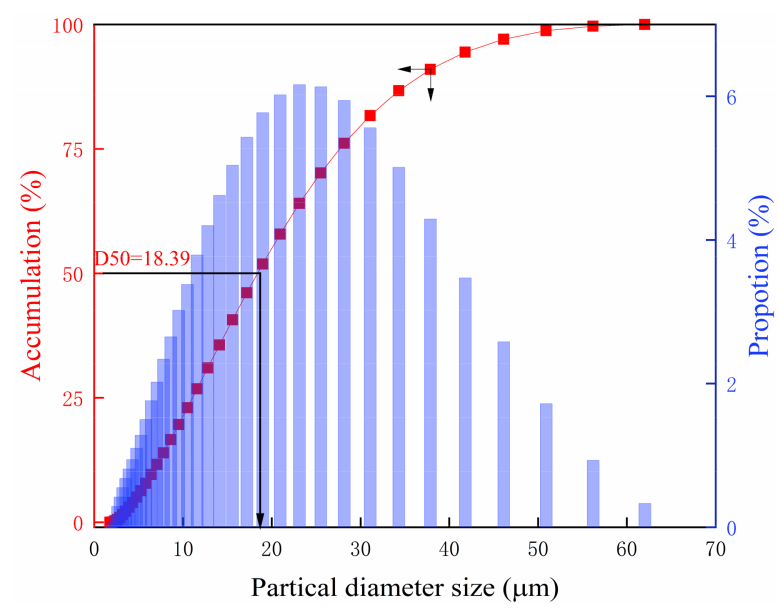

Figure 7. Particle size distribution of clean coal using emulsified kerosene as a collector. 


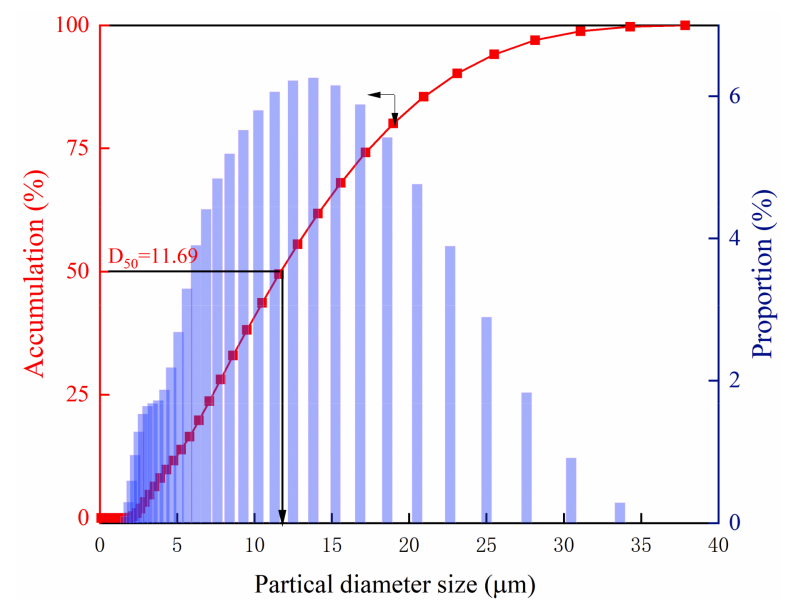

Figure 8. Particle size distribution of clean coal using only kerosene as collector.

\subsection{Improvement of the Oxidized Coal Surface Hydrophobicity}

\subsubsection{Contact Angle}

As shown in Figure 9, the contact angle of oxidized coal is increased when coal particles were treated with kerosene and emulsified kerosene. The use of emulsified kerosene produced a greater contact angle for oxidized coal than that of kerosene only. It is revealed that both kerosene and emulsified kerosene can improve the hydrophobicity of the oxidized coal surface.

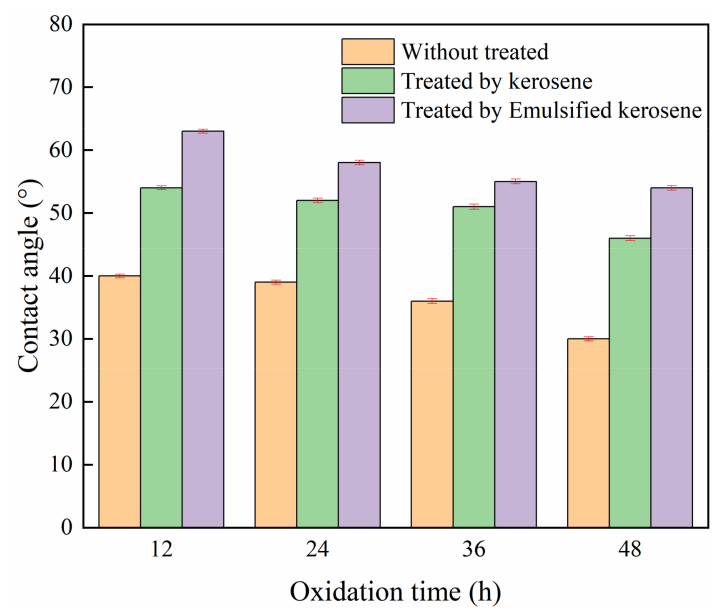

Figure 9. Contact angles of oxidized coals treated with kerosene and emulsified kerosene. For conventional conditions (only kerosene), the collector and dosage were $500 \mathrm{~g} / \mathrm{t}$ kerosene. For the mixture reagent (emulsified kerosene), the equivalent kerosene dosage was also kept as $500 \mathrm{~g} / \mathrm{t}$ as a control test.

\subsubsection{Oil Droplet Size}

The finer the oil droplet size, the more stable the emulsification is. A comparison of oil droplet size between kerosene and emulsified kerosene is given in Figure 10. It can be seen from Figure 10 that $50 \%$ of the kerosene droplets without LDD are found to have a droplet diameter of $1.2-2.3 \mu \mathrm{m}$, and $97 \%$ of the droplets have a diameter of $1.2-3.1 \mu \mathrm{m}$. On the other hand, when LDD is added, nearly $50 \%$ of the droplets are smaller than $1 \mu \mathrm{m}$, there are no droplets larger than $2 \mu \mathrm{m}$ in diameter, and $97 \%$ of the droplets are from $0.1-1.6 \mu \mathrm{m}$ in diameter. The smaller oil droplet size is attributed to the low surface tension in the presence of LDD (Figure 11). The presence of LDD can produce a better dispersion state of kerosene in water and smaller oil droplets, which leads to the enhanced collision probability between graphite particles and oil droplets [27]. Under the same dosage of emulsified kerosene, the smaller droplets have a greater specific surface area, which is conducive to 
colliding with, adhering to, and spreading onto the sample particles, rendering them more hydrophobic [28]. Hence, the emulsification of kerosene contributes to improved flotation yields for oxidized coal.

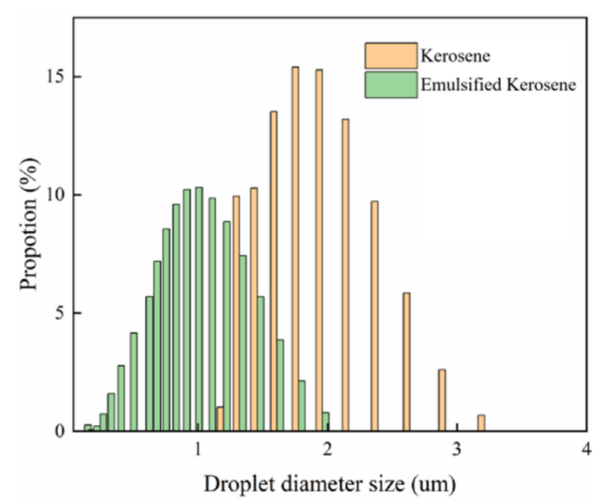

(a)

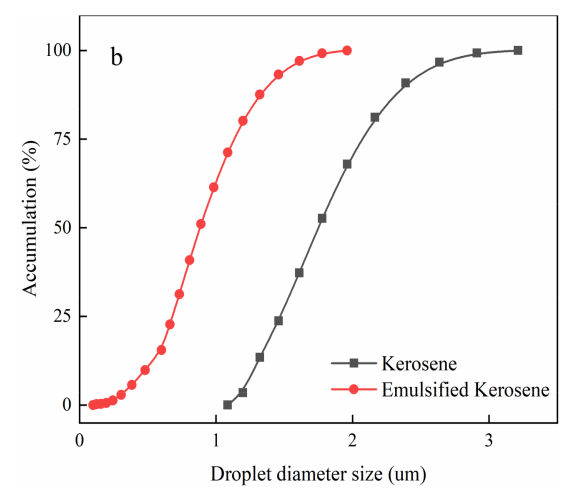

(b)

Figure 10. Size distribution of oil droplet (kerosene vs emulsified kerosene) (a) the size probability distribution; (b) the size cumulative distribution.

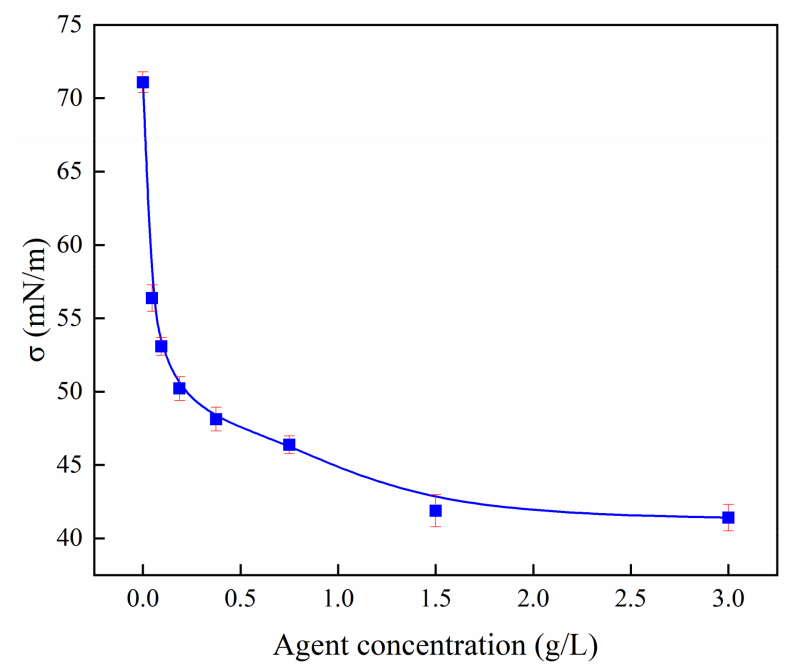

Figure 11. Surface tension under different LDD concentrations.

\subsubsection{XPS Analysis}

Figure 12 shows the fitted XPS C1s spectra of the coal surface. The binding energies at 284.6, 285.3, 286.3, and $288.4 \mathrm{eV}$, which characterize $\mathrm{C}-\mathrm{C} / \mathrm{C}-\mathrm{H}, \mathrm{C}-\mathrm{O}, \mathrm{C}=\mathrm{O}$, and $\mathrm{COOH}$ groups, respectively. The relative contents of the four groups were calculated based on the fitted peak areas [29]. Comparing the results of kerosene only and emulsified kerosene for the $12 \mathrm{~h}$ oxidized coal, the relative content of $\mathrm{C}-\mathrm{C} / \mathrm{CH}$ is $59.87 \%$ and $66.53 \%$, and the increase is $6.66 \%$. It can be seen that the content of hydrophobic functional groups is greatly increased. The relative content of oxygen-containing functional groups, such as $\mathrm{CO}$ is significantly reduced, which reduces the hydrophilicity. In addition, comparing the $24 \mathrm{~h}$ oxidized coal treated with kerosene and the $24 \mathrm{~h}$ oxidized coal treated with emulsified kerosene, it is found that the content of $\mathrm{C}-\mathrm{C} / \mathrm{C}-\mathrm{H}$ hydrophobic functional groups increased from $57.28 \%$ to $64.24 \%$, an increase of $6.96 \%$ [30]. It can be seen that the relative content of hydrophobic functional groups has been greatly increased. Because LDD has a profound adsorption effect on oxidized coal surface. The reason is that $-\mathrm{NH}_{2}$ contained in LDD often forms hydrogen bonds with nearby strong electronegative atoms, such as oxygen and nitrogen, it easily reacts with the polar oxygen-containing and nitrogen-containing sites of low-rank coal, resulting in the exposure of non-polar hydrophobic hydrocarbon chain 
ends. Aside from emulsifying kerosene, LDD can also adsorb on the coal surface, resulting in an increase in hydrophobicity on the oxidized coal surface.
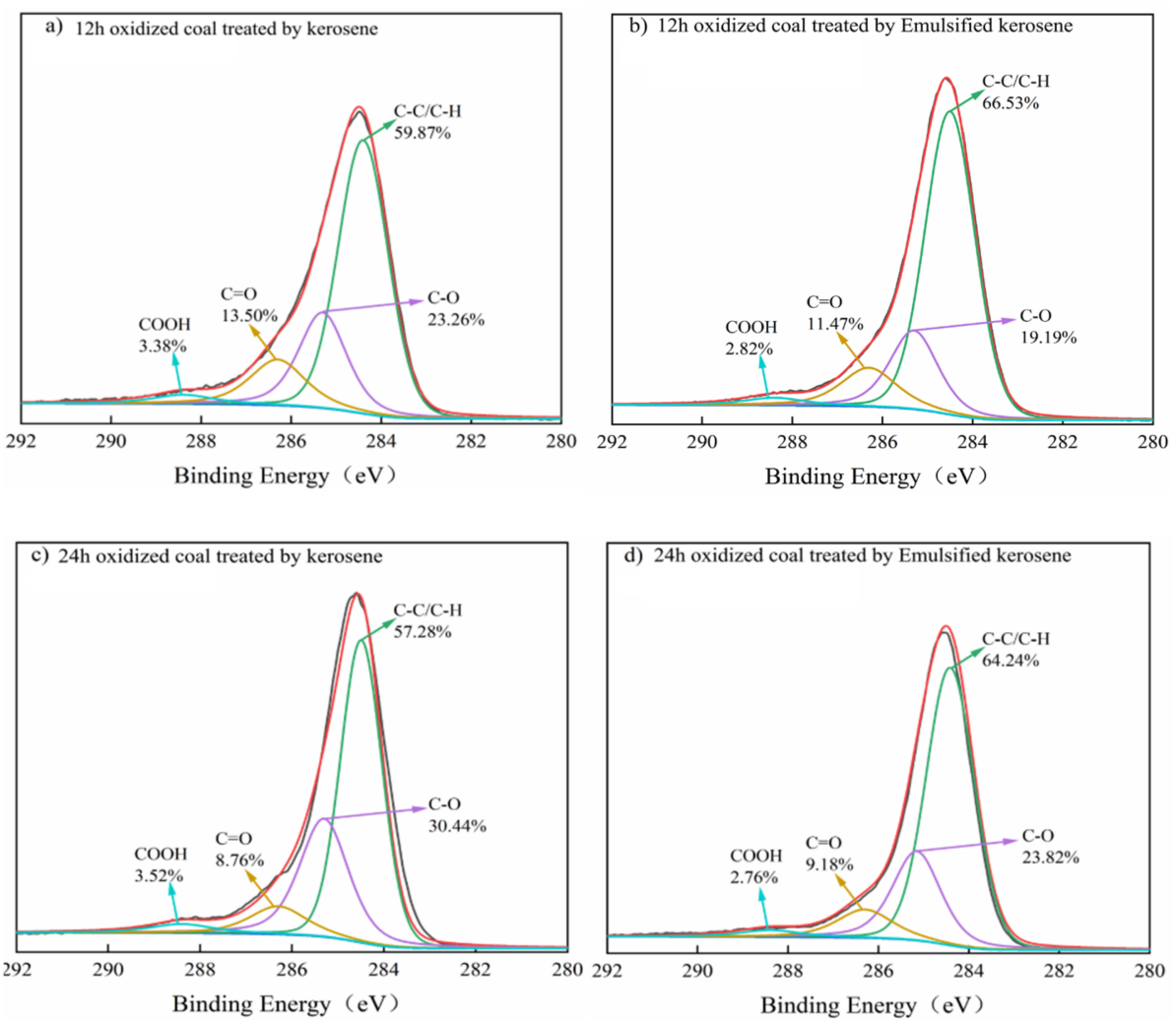

Figure 12. Fitted XPS C1s spectra of coal with different oxidation degrees treated by kerosene and emulsified kerosene. For conventional conditions (only kerosene), the collector and dosage were $500 \mathrm{~g} / \mathrm{t}$ kerosene. For the mixture reagent (emulsified kerosene), the equivalent kerosene dosage was also kept as $500 \mathrm{~g} / \mathrm{t}$ as a control test. Black line: the original data of XPS test. Red line: the data fittied by XPSPEAK 4.1 software.

\subsubsection{FTIR Results}

The floatability of coal is related to its surface wettability, and its wettability is determined by the content of hydrophilic functional groups and hydrophobic functional groups on the surface. The higher the hydrophobic organic carbon content on the coal surface, the stronger the hydrophobicity and the better the floatability.

Figure 13 shows the FTIR analysis of coal under $24 \mathrm{~h}$ oxidation conditions after different treatments, and its absorption peaks are shown in the figure. The infrared spectrum of the coal sample shows that the peaks near $3430 \mathrm{~cm}^{-1}$ and $1600 \mathrm{~cm}^{-1}$ belong to the stretching vibration of $-\mathrm{OH}$ and $-\mathrm{C}=\mathrm{O}$, after being treated with kerosene, the peak area is reduced. After being treated with emulsified kerosene, the peak area is significantly reduced, but due to the moisture in the air in the experiment, the $-\mathrm{OH}$ peak area is unstable. The peaks near $2920 \mathrm{~cm}^{-1}, 2850 \mathrm{~cm}^{-1}$, and $1450 \mathrm{~cm}^{-1}, 1380 \mathrm{~cm}^{-1}$ belong to the stretching vibration of $-\mathrm{CH}_{2}$ and $-\mathrm{CH}_{3}$, respectively, the increase in the area of these peaks indicates that the content of hydrophobic functional groups in the coal sample is increased. In the oxidized coal, treated with kerosene and emulsified kerosene, the coal treated with emulsified kerosene has a larger area of these peaks, indicating that kerosene is effectively dispersed and adsorbed on the surface of the coal. The peaks near $3320 \mathrm{~cm}^{-1}$ and $3180 \mathrm{~cm}^{-1}$ belong to the stretching vibration of $-\mathrm{NH}_{2}$. The oxidized coal treated with emulsified kerosene has this adsorption peak, it shows that LDD has a certain amount of adsorption on its surface, which has a positive effect on the process of coal particles being collected. After LDD is adsorbed on the surface of oxidized coal, its hydrophilic end and 
the hydrophilic end of oxidized coal are adsorbed to each other through the hydrophobic bridge provided by van der Waals force, so that the hydrophilic sites on the surface of oxidized coal are covered by the hydrophobic end of LDD.

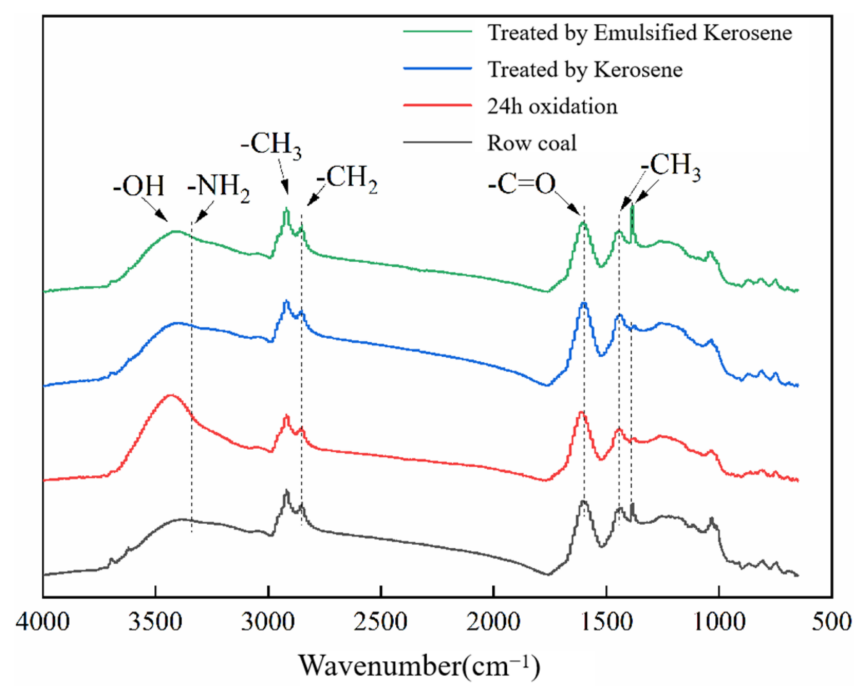

Figure 13. Functional groups on oxidized coal treated by kerosene and emulsified kerosene. For conventional conditions (only kerosene), the collector and dosage were $500 \mathrm{~g} / \mathrm{t}$ kerosene. For the mixture reagent (emulsified kerosene), the equivalent kerosene dosage was also kept as $500 \mathrm{~g} / \mathrm{t}$ as a control test.

For oxidized coal, the addition of surfactants effectively increases the content of hydrophobic functional groups, such as $\left(-\mathrm{CH}_{3}\right) /\left(-\mathrm{CH}_{2}\right)$, effectively reducing the content of hydrophilic functional groups, such as $(-\mathrm{OH}) /(-\mathrm{C}=\mathrm{O}) /(-\mathrm{COOH})$. This result is consistent with the XPS, contact angle, and flotation results.

\subsection{Generation of a Stable Froth}

As a surfactant, LDD not only interacts with the oxidized coal surface but also adsorbs at the gas-liquid interface, which will greatly change the froth properties. As shown in Figure 8 , a very small amount of LDD can cause a large drop in surface tension, from $71.083 \mathrm{mN} / \mathrm{m}$ to $56.375 \mathrm{mN} / \mathrm{m}$. When its concentration exceeded a certain value, the surface tension of the solution remained at about $41 \mathrm{mN} / \mathrm{m}$. This is because if the concentration of surfactant exceeds a certain value, micelles are produced [23]. As seen in Figure 14, the emulsified kerosene can produce a large number of bubbles in the froth zone compared to that of the kerosene and sec-Octyl alcohol combination. The comparison of the side-view photos of froth in the presence of (a) kerosene and (b) emulsified kerosene is given in Figure 15. The froth height in the absence and presence of LDD are $6 \mathrm{~mm}$ and $30 \mathrm{~mm}$, respectively. This phenomenon indicates LDD can produce a more stable froth, which is due to the significant reduction of the surface tension (see Figure 8). It is concluded that the stability of the froth plays an important role in the recovery of oxidized coal particles in this study. This finding is similar to the study of Ni et al [30]. They demonstrated that the enhancement of the froth properties (increasing the maximum froth height and half-life time) by Tween 80 was the main reason for the increase in the combustible matter recovery of lignite in flotation [31]. 


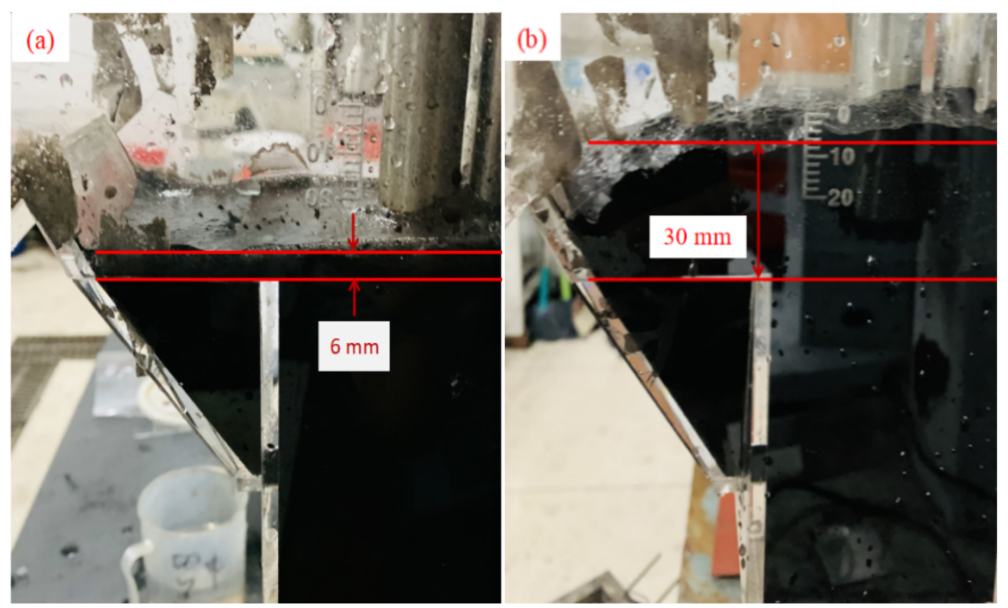

Figure 14. Top-view photos of froth produced in the presence of (a) kerosene and (b) emulsified kerosene. For conventional flotation (kerosene+ sec-Octyl alcohol), the collector and frother dosages were $500 \mathrm{~g} / \mathrm{t}$ kerosene and $167 \mathrm{~g} / \mathrm{t}$ sec-Octyl alcohol, respectively. For the mixture reagent (emulsified kerosene), the equivalent kerosene dosage was also kept as $500 \mathrm{~g} / \mathrm{t}$ as control test.
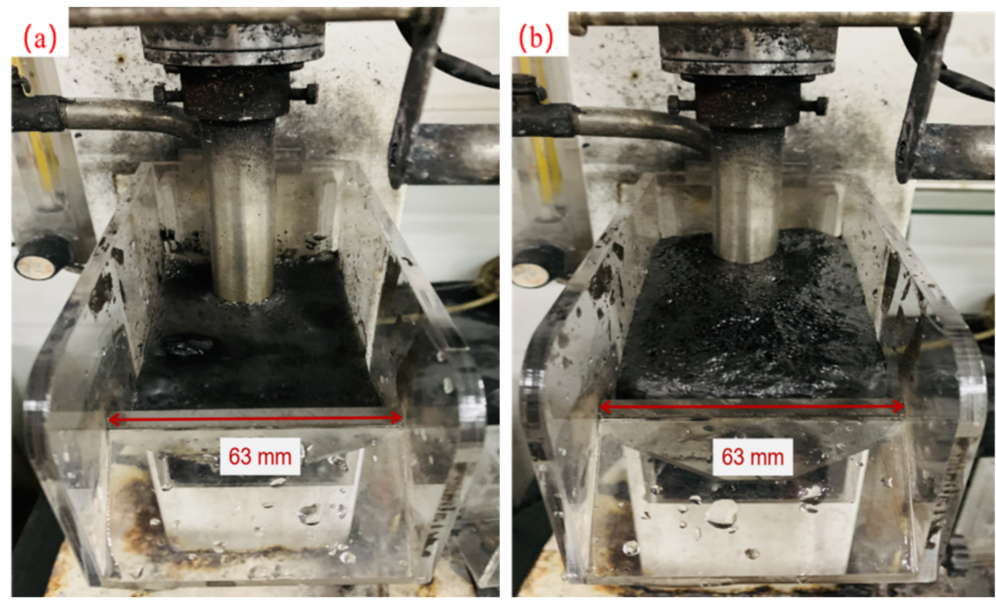

Figure 15. Side-view photos of froth produced in the presence of (a) kerosene and (b) emulsified kerosene. For conventional flotation (kerosene+ sec-Octyl alcohol), the collector and frother dosages were $500 \mathrm{~g} / \mathrm{t}$ kerosene and $167 \mathrm{~g} / \mathrm{t}$ sec-Octyl alcohol, respectively. For the mixture reagent (emulsified kerosene), the equivalent kerosene dosage was also kept as $500 \mathrm{~g} / \mathrm{t}$ as a control test.

\section{Conclusions}

This paper investigates the feasibility of LDD to improve the flotation performance of low-rank coal from the perspectives of the hydrophobicity of the coal surface and the froth stability. The main conclusions are as follows:

(1) LDD, an amine derivative, has excellent antistatic, emulsifying, lubricating, solubilizing, antibacterial, sterilizing, and anticorrosive properties. It is an environmentally friendly agent.

(2) The hydrophilic functional groups of LDD adsorb the hydrophilic sites on the coal surface through hydrogen bonds, exposing the hydrophobic end to the bubbles, which makes the content of hydrophobic functional groups on the coal surface vary greatly, and the hydrophobic end may cover part of the hydrophilic sites on the coal surface. It provides a "hydrophobic bridge" that adheres to kerosene through van der Waals forces, enhancing the hydrophobicity of the coal surface. 
(3) The addition of LDD reduces the surface tension of the solution from $72 \mathrm{mN} / \mathrm{m}$ to $41 \mathrm{mN} / \mathrm{m}$. For emulsified kerosene, smaller oil droplets can be formed, which improves the efficiency of kerosene.

(4) LDD offsets the adverse effects of collectors (kerosene) on the froth layer, greatly increasing the height of the froth layer. In addition, due to the foaming performance of the emulsifier, no additional foaming agent is needed, which greatly reduces the production cost.

(5) For oxidized coal with $12 \mathrm{~h}$ of oxidation time, the flotation yield increased from around $20 \%$ (using kerosene only) to around $40 \%$ (using emulsified kerosene).

Author Contributions: Conceptualization, C.N. (Chao Ni) and X.B.; methodology, investigation, software, validation, and formal analysis Q.Z. and C.N. (Chenkai Niu); resources, Y.P. and C.N. (Chao Ni); data curation, C.N. (Chao Ni) and X.B.; writing-original draft preparation, Q.Z. and X.B.; writingreview and editing and visualization, X.B. and M.B.; supervision, project administration, and funding acquisition, X.B. All authors have read and agreed to the published version of the manuscript.

Funding: This work is supported by the Fundamental Research Funds for the Central Universities (No. 2019XKQYMS18).

Acknowledgments: The authors acknowledge technique support from Xinxin Yan.

Conflicts of Interest: The authors declare no conflict of interest.

\section{References}

1. Zhang, R.; Xia, Y.; Guo, F.; Sun, W.; Cheng, H.; Xing, Y.; Gui, X. Effect of microemulsion on low-rank coal flotation by mixing DTAB and diesel oil. Fuel 2020, 260, 116321. [CrossRef]

2. Tan, J.; Cheng, H.; Wei, L.; Wei, C.; Xing, Y.; Gui, X. Using low-rank coal slime as an eco-friendly replacement for carbon black filler in styrene butadiene rubber. J. Clean. Prod. 2019, 234, 949-960. [CrossRef]

3. Xia, W.; Niu, C.; Ren, C. Enhancement in floatability of sub-bituminous coal by low-temperature pyrolysis and its potential application in coal cleaning. J. Clean. Prod. 2017, 168, 1032-1038. [CrossRef]

4. Xia, W.; Yang, J.; Liang, C. A short review of improvement in flotation of low rank/oxidized coals by pretreatments. Powder Technol. 2013, 237, 1-8. [CrossRef]

5. Xia, Y.; Yang, Z.; Zhang, R.; Xing, Y.; Gui, X. Performance of used lubricating oil as flotation collector for the recovery of clean low-rank coal. Fuel 2019, 239, 717-725. [CrossRef]

6. Li, L.; Lu, X.; Qiu, J.; Liu, D. Effect of microemulsified collector on froth flotation of coal. J. S. Afr. Inst. Min. Metall. 2013, 113, 877-880.

7. Dey, S. Enhancement in hydrophobicity of low rank coal by surfactants-A critical overview. Fuel Process. Technol. 2012, 94, 151-158. [CrossRef]

8. Leja, J. Surface Chemistry of Froth Flotation; Springer: Boston, MA, USA, 1981.

9. Chander, S.; Mohal, B.; Aplan, F. Wetting behavior of coal in the presence of some nonionic surfactants. Colloids Surfaces 1987, 26, 205-216. [CrossRef]

10. Moxon, N.; Bensley, C.; Keast-Jones, R.; Nicol, S. Insoluble oils in coal flotation: The effects of surface spreading and pore penetration. Int. J. Miner. Process. 1987, 21, 261-274. [CrossRef]

11. Fuerstenau, D.W.; Harris, G.H.; Jia, R. Nonionic Surfactants as Collectors for the Flotation of Oxidized and/or Low-Rank Coal. ACS Symposium Series 1999, 740, 230-247. [CrossRef]

12. Zhu, X.; He, M.; Zhang, W.; Wei, H.; Lyu, X.; Wang, Q.; You, X.; Li, L. Formulation design of microemulsion collector based on gemini surfactant in coal flotation. J. Clean. Prod. 2020, 257, 120496. [CrossRef]

13. Liu, Y.; Liu, S. Wettability Modification of Lignite by Adsorption of Dodecyl Based Surfactants for Inhibition of Moisture Re-adsorption. J. Surfactants Deterg. 2017, 20, 707-716. [CrossRef]

14. Li, Y.; Xia, W.; Peng, Y.; Xie, G. A novel coal tar-based collector for effective flotation cleaning of low rank coal. J. Clean. Prod. 2020, 273, 123172. [CrossRef]

15. Chen, S.; Wang, S.; Li, L.; Qu, J.; Tao, X.; He, H. Exploration on the mechanism of enhancing low-rank coal flotation with cationic surfactant in the presence of oily collector. Fuel 2018, 227, 190-198. [CrossRef]

16. Vamvuka, D.; Agridiotis, V. The effect of chemical reagents on lignite flotation. Int. J. Miner. Process. 2001, 61, 209-224. [CrossRef]

17. Zhen, K.; Zhang, H.; Zheng, C. Wettability modification and flotation intensification of low-rank coal with dodecyltrimethylammonium chloride addition. J. Therm. Anal. Calorim. 2019, 137, 2007-2016. [CrossRef]

18. Farrokhpay, S. The significance of froth stability in mineral flotation-A review. Adv. Colloid Interface Sci. 2011, 166, 1-7. [CrossRef] [PubMed] 
19. Zhang, W.; Finch, J.A. Effect of solids on pulp and froth properties in flotation. J. Central South Univ. 2014, 21, 1461-1469. [CrossRef]

20. Ni, C.; Bu, X.; Xia, W.; Liu, B.; Peng, Y.; Xie, G. Improving lignite flotation performance by enhancing the froth properties using polyoxyethylene sorbitan monostearate. Int. J. Miner. Process. 2016, 155, 99-105. [CrossRef]

21. Niu, C.; Xia, W.; Xie, G. Effect of low-temperature pyrolysis on surface properties of sub-bituminous coal sample and its relationship to flotation response. Fuel 2017, 208, 469-475. [CrossRef]

22. Chen, S.; Tang, L.; Tao, X.; He, H.; Chen, L.; Yang, Z. Enhancing flotation performance of low rank coal by improving its hydrophobicity and the property of oily bubbles using 2-ethylhexanol. Int. J. Miner. Process. 2017, 167, 61-67. [CrossRef]

23. Chen, S.; Tang, L.; Tao, X.; Chen, L.; Yang, Z.; Li, L. Effect of oxidation processing on the surface properties and floatability of Meizhiyou long-flame coal. Fuel 2017, 210, 177-186. [CrossRef]

24. Bu, X.; Xie, G.; Chen, Y.; Ni, C. The Order of Kinetic Models in Coal Fines Flotation. Int. J. Coal Prep. Util. 2017, 37, 113-123. [CrossRef]

25. Li, E.; Lu, Y.; Cheng, F.; Wang, X.; Miller, J.D. Effect of oxidation on the wetting of coal surfaces by water: Experimental and molecular dynamics simulation studies. Physicochem. Probl. Miner. Process. 2018, 54, 1039-1051.

26. Xia, W.; Yang, J. Effect of pre-wetting time on oxidized coal flotation. Powder Technol. 2013, 250, 63-66. [CrossRef]

27. Shi, Q.; Liang, X.; Feng, Q.; Chen, Y.; Wu, B. The relationship between the stability of emulsified diesel and flotation of graphite. Miner. Eng. 2015, 78, 89-92. [CrossRef]

28. Chaudhuri, S.; Kalyani, V.K.; Charan, T.G.; Kumari, S.; Sinha, A. Improved Collector for Beneficiation of Low-Volatile Medium Ash Clean Coal Fines by Froth Flotation. Int. J. Coal Prep. Util. 2014, 34, 321-331. [CrossRef]

29. Niu, C.; Xia, W.; Li, Y.; Bu, X.; Wang, Y.; Xie, G. Insight into the low-rank coal flotation using amino acid surfactant as a promoter. Fuel 2022, 307, 121810. [CrossRef]

30. Nunes, A.P.L.; Peres, A.E.C.; de Araujo, A.C.; Valadão, G.E.S. Electrokinetic properties of wavellite and its floatability with cationic and anionic collectors. J. Colloid Interface Sci. 2011, 361, 632-638. [CrossRef]

31. Pugh, R. Foaming, foam films, antifoaming and defoaming. Adv. Colloid Interface Sci. 1996, 64, 67-142. [CrossRef] 